\title{
NARRATIVES FROM CALL SHOP USERS: EMOTIONAL PERFORMANCE OF VELOCITY
}

\author{
SIMONE BELLI, ROM HARRÉ AND LUPICINIO IÑIGUEZ
}

\begin{abstract}
In recent years, the debate on emotions has been influenced by postconstructionist research, particularly the use of performativity as a key concept. According to Judith Butler $(1993,1997)$ the construction of emotions is a process open to constant change and redefinition. The final result of emotionlanguage "natural" development is what is known as technoscience. New ways of naming emotions have emerged within technoscience. In our research on the use of information and communication technologies (ICT) by cyber-café and call shop users, we came to understand how these technologies are significant in those users' daily life. The emphasis will be on analyzing emotions related to the use of ICT in the aforementioned settings. Using the concept of performance (Butler, 1990), we will explore how narratives create a need for particular emotions, which did not exist before they were performed. To understand this performance, we use an ad hoc tool called Membership Categorization Analysis (MCA) as it is used by the Manchester School. Analysis has revealed the existence of a membership category in which velocity is salient as performance. This 'velocity' seems to follow the evolution of technoscience in the social sciences. We will observe velocity in the context created by two concepts, Donna Haraway's (1990) cyborg and Alessandro Baricco's (2007) mutant.
\end{abstract}

Keywords: emotions; performance; velocity; Membership Categorization Analysis (MCA); information and communication technology (ICT).

In recent years, the debate on emotions has been influenced by postconstructionist research (Íñiguez, 2005), particularly the use of performativity as a key concept. According to Judith Butler (1993), the construction of emotions is a process open to constant change and redefinition (Butler, 1997). In this vein, the "natural" evolution of emotion and language has ultimately led to the appearance of technoscience. New ways of naming emotions have emerged from a technoscience perspective (Belli, S., Harré, R., \& Íñiguez, L., in press). Information and communication technologies (ICT) have resulted in new emotional aspects which philosophers, psychologists, and epistemologists have targeted in their common interests, for instance, the affective machine (Rose, 1983; Brown, 2005; Brown \& Stenner, 2001; Michael, 2000, 2006), the notions of cyborg and techno-disembodiment (Haraway, 1989, 1995; James \& Carkeek, 1997; Gibbs, 2006; Hollinger, 2000), or the notion of "disclosure", a fuzzy phenomenon meaning the expression of emotions through a screen.

In our research on the use of information and communication technologies (ICT) by cyber-café and call shop users, we have come to understand how these technologies are signifi- 
cant in users' daily lives. The emphasis has been on analyzing emotions related to the use of these technologies in these two specific settings. Using the concept of performance (Butler, 1990), we explore how narrative constructs a need for particular emotions, which did not exist before the performance. These performances are seen as natural through their repetition over time. They are a set of multiple everyday social interactions. To understand performance in narrative, it is necessary to use a "tool". In our case the tool is called Membership Categorization Analysis (MCA), as used by the School of Manchester (Leudar, 1995, 1998).

The symbiosis between emotions and ICT opens up a new area of study in which emotion is understood as a symbolic process depicted by narrative at its best. For this reason it is fundamental to see emotion as a process linked to the way people approach and use ICT. Analysis has revealed that velocity is a salient membership category. It is constructed by users through narrative as a performative and primarily emotional process. Thus, discursively produced 'velocity' seems to follow the evolution of technoscience in the social sciences, through the concept of the cyborg (Haraway, 1990) and the concept of the mutant (Baricco, 2008).

Haraway's concept of the cyborg helps us understand why the relationship between the individual and the machine is like an extension of the person, created by discursive performance. We will use this relationship, constructed through narrative, to help us to introduce what we will talking about in this article, that is, an analysis of ICT users' interviews in which a new emotional performance emerges. As already asserted, we believe that the use of ICT as an extension of a person's body, as held in the concept of the cyborg, is constructed through language. Hence, its use is always discursive. The discursively performative use of ICT constructs the relationship, or conflict, between the individual and society in a continual iteration of speech acts.

\section{What is an emotional performance?}

When it comes to performance in postconstructionist studies the name of Judith Butler is surely the most important. Butler $(1993,1997)$ considers emotion as a process constantly evolving in contemporary narratives. She offers a completely new perspective on the depiction of emotions through the concept of performance. Although the term "emotion" is not explicit in her writing, it spontaneously arises out of people's narratives and positions. Using the concept of performance, Butler explores how narrative creates a need for particular emotions:

... acts, gestures, enactments, generally construed, are performative in the sense that the essence or identity that they otherwise purport to express are fabrications manufactured and sustained through corporeal signs and other discursive means (Butler, 1990, p. 136).

In this way, emotion is a performance produced by these constructions. It is comprised of acts which are internally discontinuous, i.e., emotions do not exist prior to being performed. There cannot exist a successful "copy" of an emotion which one could expect to use to faithfully reproduce a previous event or a new emotion. Performances are seen as natural through their repetition over time. They eventually become standards and they come to be seen as normal, taken as a set of multiple daily social interactions. 
Therefore, the concept of performativity in Butler is an attempt to find a way to rethink the relationship between social structures and individual agencies. In Butler's interpretation, performativity is understood as that which promotes and supports the implementation of certain processes through iterations constrained by certain rules. Such standards should be understood in a Wittgensteinian vein, as a spontaneous discursive increase in our feelings. We assume that words refer to purely spontaneous processes (Wittgenstein, 1958). Since rules are valid only for a particular context, and only for some people, they cannot be duplicated and applied in different situations. The politics of performativity requires the iterative power of narrative to produce the phenomenon of emotion, for emotion does not exist before we say something, before speech is produced. Emotions are designed as socially constructed phenomena, and at the same time they construct a social identity which determines that the audience has to behave as a performer (Butler, 1990). As explained above, emotions do not exist prior to being performed, and they cannot be reused and categorized and listed afterwards (Gregson \& Rose, 2000, p. 438).

\section{Finding performance in narrative}

A key task for researchers is to find the theory in the practice, that is to say, find performance in narrative. Using MCA, we have fulfilled our objective of understanding the role of performance in the study of emotions in ICT settings.

MCA is a formal analysis of the procedures people use to make sense of other people and their activities. Sacks (1992) developed MCA on the basis of the work of Lacan and Chomsky, and his then colleague, Emanuel Schegloff. Harold Garfinkel also helped shape the MCA from an ethnomethodological perspective. He established that the method should involved depicting the way in which people categorize themselves. Membership categories are comprised of "categories related to predicates, which may include dispositions, acts, tasks, beliefs, and values" (Watson, 1987). Most of the MCA categories are relatively distinct (e.g. "mother", "son") and we can discuss how these categories are used in narrative. But one of the main problems is that these categories are treated as if they were fixed. This problem emerges especially in studies of the social and political identity of the body, for new categories appear and disappear throughout the analysis. This categorization transcends and implies narrative. That is, we are interested in how participants manage the relationship between categories (Leudar, 1998). The way they do this is categorized into "collections", "classes", and "relationships". But, in our research, what interests us most is what Leudar (1998) calls a "distributed discursive network", that is, how categories and relationships interactively emerge from narrative (Leudar, 1995, 1998).

Ivan Leudar's perspective differs from Sacks' view because of the particular way in which he understands "categories" of codes. According to Leudar, these "categories" of codes constantly evolve within narrative. They are never fixed. Instead they change continuously, and a member of a code can often change the category itself. It is an open and circular dialogic process. This change in category can be perceived owing to linguistic and lexical factors produced in social practices.

Another important aspect of Leudar's approach is that categories must be active; this is the key difference between his conception of MCA and Sacks'. Leudar depicts categories as 
an open system which, at the same time, constantly evolves, coming and going from open to closed and vice versa.

\section{Emotions in technoscience}

We saw that emotions have a strong relationship with language (Belli \& Íñiguez, 2008), especially with regards to the concept of performance (Butler, 1990). We will focus now on the "effects" in everyday language. Performance is better understood when we observe that some emotions appear and disappear in ordinary discourse. This is because emotions are embedded in narratives. They are speech-acts (Oatley \& Jenkins, 1992, p.75).

Performance is subject to the power of the narrative of emotions. The narrative of emotions is full of smaller narratives on new concepts and metaphors that serve to articulate the lexicon of emotional words. Concepts such as techno-disembodiment and the human-affective machine are the techno-scientific side of emotions. They represent new performances, new emotions appearing in the discursive arena.

Emotions keep on changing in the natural and spontaneous language of everyday life. New words enter the discursive arena thanks to performance. Thus, new areas are created in the technology sector, like Human-Computer Interactions, Science and Technology Studies, etc. (Belli, Harré, \& Íñiguez, 2010). This is how emotions begin to enter technological narrative as another performance in everyday narrative. The concept of performance related to ICT produces new narratives in the social sciences, such as techno-disembodiment and the affective machine. Only in recent years has it been understood that emotions and new technologies have a very close relationship. This relationship can be observed frequently in affective settings: for instance, a mother speaking to her children and family on the phone while crying; an immigrant "going out" to a party with her friends in their country of origin via the Internet; a chat between young lovers who are actually separated by thousands of miles.

In recent research concerned with emotions in technoscience using a pure semiotic method, Mike Michael (1996, 2000, 2004, 2006) identifies emotions as affective matter.

These different narratives on affect and emotions in technoscience can be seen in the context offered by Nikolas Rose (1983) using the concept of affective matter and the figure of a computer-machine that constructs the individual, i.e., the affective machine. This vision is embodied in the cyborg (Haraway, 1990, 1995; Hollinger, 2000). Gergen (1990) also offers us a reinterpretation of affective matter in the postmodern society.

Steve Brown and Paul Stenner (2001; Brown, 2005) speak of collective emotions in technoscience and the consumer society, using the writings of Spinoza, as well as more recent authors, such as Schaub (1933) who states that affective matter becomes a humanmachine being.

When we find ourselves before a screen, our most intimate thoughts and feelings emerge from a generated series of mechanisms. This process has been labelled disclosure in scientific narrative fiction (Aviram \& Amichai-Hamburger, 2005; Qian \& Scott, 2007). Disclosure is one of the most striking aspects that we have found throughout the analysis of the interviews we have done for our research. Disclosure helps us to explain how we love to talk with strangers, or someone that we already know, but it is only on the screen 
that we dare to tell them things we would never say face to face, especially things we only express in private settings, like emotions themselves. This allows us to understand how these technologies are successfully used in different aspects of life. Phenomena such as Facebook ensure just that. We contact someone who we already know, but get into a more intimate mode, where we can express our hidden emotions or take public relations to another level and all through language. This kind of reasoning permits us to rethink the affective relationships, the intimate aspect of new technologies, and the emotions we experience when we are in front of a computer's screen.

An example of an affective machine is the construction of technological systems that can interact with humans and transmit bio-psychological changes, e.g. shoes, bracelets, t-shirts that receive and transmit emotional changes to the individual, so that changes in emotional states are registered in their social contexts. These gadgets are just a stage in man-machine interaction.

File-selves are of particular interest to us (Harré, 1984). For Harré, the self may be present in many different places and may take part in various episodes, though the body is actually located in one space and one time. For example, a person may be playing tennis and, at the same time, may be being evaluated via her curriculum vitae for a job, or a bank may be making a money transfer on her behalf, or police may be investigating her as a potential terrorist, etc. This is possible because any individual may feature in a large range of files, i.e., recordings of personal information. My body and my accompanying 'file-selves' go together.

If we take this example, we can understand the way in which technology has become a part of everyday life. A person is working on-line while her friends look at her photos on Facebook. They comment on them and then her boyfriend sends her an e-mail. Her mother then calls her using Skype and a co-worker sends her an SMS. In addition to these events we can begin to add ones that have been previously suggested by Harré. For these reasons, we must understand the use of new technology as an extension of the self.

Haraway's cyborg concept helps us to understand why the relationship between the individual and the machine would be like an extension of the same individual, created through discursive performances. In turn, this relationship enables us to introduce what we will try to set out in the next section, i.e., an analysis of interviews with users of new technologies in which a new emotional performance appears: 'velocity'.

\section{Emotional performance of velocity}

Use Gmail on your mobile, it's super fast! (http://mail.google.com 10th October 2008)

In interviews, emotional performance continually emerges as a membership category. It is always present, and is, no doubt, the main candidate in a study of emotions in ICT. Emotional performance emerges spontaneously and always takes on different connotations. It is growing as an ever-changing category, i.e., as performance. This phenomenon can only be understood through MCA, according to the Manchester School. As we saw before, MCA helps us to find performance in emotional narratives. Thus, for the reasons already described, 'velocity' appears as a "new” emotional performance in the technoscience discursive arena. 
Emotional performance is an extension of our body and it is used to interact with others through ICT. It is discursive since it is only through narrative that it can be constructed. It is like the concept of the cyborg (Haraway, 1990) but is entirely linguistic. We will outline what an emotional performance is in the next section and try to trace and observe its course, finding a way to define 'velocity' without minimizing the importance of the constant and continuous evolution of its performance, its iteration. We will trace the path of a particular performance through narrative analysis and MCA.

Performance has been characterized by three aspects that have emerged inductively: speed, efficacy, and ease. These three features have been useful throughout the analysis to find this performance and to understand how they are iterated.

Emotional performance is a Membership Category [MC] related to Category Bound Activities [CBA] (i.e., activities, actions, verbs) associated with ICT comprising use, progress, time, and change. Following the cyborg concept, the use of one's own body as an extension is constructed through language; in other words, this activity is always discursively constructed. Thanks to language, it is possible to define the extension, use of ICT, CBA and performance. A continuous iteration is created to relate the relationship, or conflict, between individual and society, through the use of ICT and discursive performance.

Thus, performance is based on the use of technologies. This is discursively constructed through the emotional performance of velocity. In analysis of call shop users' narratives, 'velocity' appears as a cold emotion transmitting very little, but seducing because of its own performance. Velocity goes from being cold and unemotional, or as Illouz (2007) says "a frozen emotion", and becomes a completely true emotion, not cold at all. We can see people laughing or crying in front of a screen (Belli \& Íñiguez, 2008).

The respondents we interviewed used the word ,technology" to refer to a whole list of terms related to a way of understanding emotions as cold, unemotional. This list includes design, operation, purchase, etc. It is a list of terms that cannot be regarded as similar to the way we have specified emotion before. 'Unemotional' is the usual term used to describe the emotional side of technology. The term refers to the use of a "cold" device, like the computer, to communicate with other people. The cold light of the screen (Baudrillard, 1990, p. 153) produces a cool seduction. This is the narcissistic charm of new technology, the cool charm of the Internet. But the absence of emotion, when related to the use of ICT to communicate with others, changes, evolves. It becomes a performance, an actual emotion.

\section{Extract $1^{1}$}

210. -yeah ... a lot ... because they agreed to meet at this hour ... hour, in the afternoon over there ... there ... morning over here ...

211. The web-cam is wonderful ... you see your wife and your kids ... your family ... mother or your...

212. grandparents and two ... three hours ... there ... crying. You'll see some crying ... mourning ... saying things

213. very very sweet ... then you hear and ... it hits you ... doesn't it?

\footnotetext{
${ }^{1}$ Extracts from non-native speakers call shop users' narratives.
} 


\section{Extract 2}

215. I... once I got drunk with some friends watching the webcam

216. I was ... ah ... and cheers! ... (laughs) and drank too (laughs) and we got drunk (laughs)

Good

217. and "Bye" (laughs) ... It kills yearning... the longing...

In extracts 1 and 2, we observe how here performance emerges and we can understand its "history". It is an iteration that changes from an unemotional condition, a cold emotion, until it becomes a colorful real human emotion. This will all become much clearer as we examine the extracts.

We consider it appropriate to treat the unemotional aspect of performance in the first part of the analysis, highlighting the importance of the iteration process in this performance. We continually see technology as being something cold, but suddenly, when we relate to it, we find that it produces a substantial number of real emotions. Only when an MC appears can it be identified and defined as such. Emotional performance as $\mathrm{MC}$ is flexible, open, and dynamic, and thus it may provide meaning and evolve through the narrative. Only by treating emotion as a performance, i.e., 'velocity', can we understand the iteration.

\section{Extract 3}

253. C: Interne: $t$ (.) Maybe: ye: (0.5) Internet and mo: bi: le

254. E: Yeah? (0.3) Is it more friendly?

255. C:> It's the most friendly <more fast: and (0.2) efficient.

As we mentioned earlier, the emotional performance of velocity is defined by three characteristics. These characteristics were identified by interviewees on the Internet, or more precisely, while using the Internet: "It's the most friendly, more fast and effective" (Extract 3 , line 255). However, we will try to understand emotional performance of velocity in detail through these three emotional characteristics, and establish how they help to delineate the actual iteration. We start with speed:

\section{Extract 4}

15. C:> The cyber-cafe have <technology: a:: well (.) advanced and

16. they're up-da:ted: $(0.3)$ and all> computers are <enough: s fast: $\mathrm{s}(0.2)$

17. and have flat screen, (.) The ones in the cyber: cafe: s. all have WebCams

18. They don't lack anything (.) you can hear MU: music, you can do (.) works: and (.) several 19. things

We can agree that the MC of "velocity" emerges, in terms of the interviewee, as an emotional performance. Terms such as "fast" and detailed descriptions of ICT, such as "flat screen", "have webcams", "can do", and "many things" are used. (Extract 4, line 16-17). Technological advance is continually present in the interviewee's narrative. He says "flat screen" instead of "display", when he refers to the speed of technological change. He always refers to features of technology, and to how it is continuously changing and rapidly evolving. This strict relationship between technological advancement and the use of the technology 
toward to leads to what we have previously defined as iteration. It is impossible to define, $a$ priori, what this iteration is, since it is constantly changing in discursive activity. It changes differently among people who communicate through technologies or by using them. Thus, speed relates to and redefines the nature of the distinction about progress in technology. But all this will be discussed in more detail later.

We know that speed changes depending on advances in new technologies. Speed is never a fixed state and it is continually changing. It is a continuous motion in narrative. It is a constant iteration as the Butlerian concept of performance (Butler, 1990).

\section{Extract 5}

73. Soon I will buy a PDA or a Blackberry.

\section{Extract 6}

85. See it, (0.4) perhaps:: I (.) I am abroad (.) and there is a pressing problem (0.3) and I can 86. answer: (0.2) and be able to answer from two thousand kilometers. (0.3) I think

87. These are good:, (0.3) thing: s: aren't they?

\section{Extract 7}

101. C: with all the advantages (0.3) they:'ve improved it

\section{Extract 8}

105. lasting. (0.5) I am a person is (0.2) using Mobile phone(0.4)

106. (0.3) has changed mo: bile three: or four time: $s$

107. E: Yes

108. C: I am not interested: in change: it $(0.2)$ every six months, $(0.4)$ every year $(0.2)$ 'cause:

109. I found: >not that much<

Terms like "soon" (Extract 5, line 73), "pressing problem" (Extract 6, line 85), "improved it" (Extract 7, line 101), "changed mobile three or four times" (Extract 8, line 106 ), "I am not interested in change it every six months (Extract 8, line 108), refer to continuous temporal change. The relationship between speed and the use of ICT is directly related to time and space.. You cannot repeat that emotional performance in other areas. The success of a copy of that emotional performance in others contexts is destined to fail. We must understand that time and space are on the move and this movement prompts the performance.

\section{Extract 9}

354. many people spend their lives in the workplace 355. and have no time to go out and interact with people, so

356. they go to the computer and try to meet people, that's it 


\section{Extract 10}

424. I'm looking for a room, and it's a very effective way in my case. I once

425. found a room on the Internet which is faster, the whole

426. craigslist webpage, where people look for job postings

427. rooms for rents, and things like these. This is the advantage.

As discussed above, time reappears. This is the time which the interviewee does not have, which escapes him. The pressing issues, answering mails quickly, as seen previously (Extract 6, lines 85-86), mean that he did not have time for other things, such as meeting people. "Il tempo si fa breve" says Saint Paul of Tarsus, and due to higher velocity new technologies allow us to extend time, or to enjoy time in a better way, or to waste it in a more entertaining way, for example, Facebook. A strong and steady performance, evolves and revolutionizes the social relationships of every individual.

The Internet makes tasks more effective (Extract 10, line 424-427). A number of examples help us understand how the use of these new technologies make it more effective, faster, and easier for us to undertake our tasks on a daily basis. The performance of 'velocity' is constructed in everyday life.

As Bauman explains (2006), time has changed, and he uses the example of make-up commercials. Make-up lasts for a long-time. It has to last for a considerable amount of time. But in the commercial Bauman analyzes, the length of time is only 24 hours, i.e., it is assumed that ' 24 hours' is a long time. It is a new ratio for measuring time, similar to that used by people meeting people through Meetic as will be explained later. Another example that the time has changed is searching for information on Google. You type "Radiohead" and in 0.17 seconds you have 27,000,000 references. If you type "Bauman", in 0.40 seconds you have 3,199,000 references. Time has changed to look information. Nowadays, thanks to technology, we have more information in less time. Consumption information is fast, as is the consumption of technology.

But velocity for some users is an MC which becomes a "pressing problem" (Extract 6, line 85). We need a way to resolve these urgent issues as quickly as possible, and this speed, this efficacy, this velocity can only be achieved by purchasing, as the interviewee says, a PDA or a Blackberry:

\section{Extract 11}

73. Soon I will buy a PDA or a Blackberry.

Technological change is the solution, and this change always has to be developed under 'velocity' understood as an emotion.

Just purchasing the technology produces a range of emotions in the individual. The happiness experienced on purchasing a new Blackberry or the boredom of still having a previous version are reasons for wanting to change. In discursive terms, change and technological advance are issues which fall under the emotional performance of velocity. Perhaps, the individual has a series of emotions, but we can only know what she is feeling if she expresses it. Then, she uses new emotional terms, new words for explaining emotions 
that already exist. This coincides with the change in the discursive arena. We use new terms when discussing the relationship between individual and new technologies.

The second feature of this emotional performance is efficacy:

\section{Extract 12}

175. databases, in this case Excel, and soon Saf. I can

176. use Saf software. As many people know, it's a program

177. really good and effective, which has different modules. In my

178. business, in this case, it has modules of accounting, for

179. the whole company's accounting. It's good to have all the

180. products of the company checked at any time.

181. You can see them, and then what other departments such as the commercial department do.

The characteristic of efficacy can be found at line 177, Extract 12: "really good and effective". This second feature of velocity, throughout the analysis, is related to two Bound Activities (BA), which we have seen before: progress and time. "Soon Saf" (Extract 12, line 175), refers to the technological advancement of this specific software data management in companies, and "checked at any time" (Excerpt 12, line 180) is an example of efficacy in its purest form.

For these reasons, we consider efficacy a key feature of velocity. It always depends on technological improvements and the use of time. For example, "any time" (Excerpt 12, line 180) refers to instant, to fast.

\section{Extract 14}

132. C: Yeah, well, a mp4, that they gave me and I haven't had time to

133. use it. Yeah I've a mp4 for my birthday, but

134. E: Yeah?

135. C: I have had little time. Even I don't have time to sit and watch it ((mp4))

136. and learn things

\section{Extract 15}

16. E: (1.3)>Eh with computer< it's possible to

17. communicate more easily: (0.2) becau:se: you don't pay

18. any: fee: $\mathrm{s},(0.2)$ Howe:ve:r, with mobile-phone is

19. more expensive

The concept of time emerged as a crucial component in understanding velocity as an emotional performance. Obviously, there is a very strict relationship between velocity and time, which is the most frequent relation between $\mathrm{MC}$ and BA. One of the basic functions of this emotional performance is to gain time: "I have had little time. Even I don't have time to sit" (Extract 14, line 135). There is a continuous race against time. The performance occurs as a struggle between gaining time and losing it. For this reason, the concept of gaining time, or losing time, introduces us to the third feature of this performance, 'ease'. 
As seen above, performance cannot be understood in isolation from the use of ICT. We have seen what speed and efficacy mean, but for the performance of velocity to be complete, it is necessary to define 'ease'. We think of the ease of communicating, for example: "It's possible to communicate more easily" (Extract 15, line 16-17). But we have to learn to use the device. We have to read instructions. Using a new technology always involves the time it takes to set up and to learn how to use it. As we have said before, one of the aims of achieving velocity is to gain advantage in the tremendous battle against time, and it is for this reason that ease is one of velocity's main features. When things are easy we gain time, but where systems and practices are complicated, we lose time.

Thus these three characteristics, speed, efficacy, and ease, define the continuous performance of velocity.

As we said in the first part of this section, individuals use new technology as an extension of their own bodies, as in Donna Haraway's concept of the cyborg, but discursively so as to interact with others. This implies activities that allow us to maintain our social relationships, our social context.

\section{Extract 16}

275. C: it also promotes social and emotional. For what

276. was once a marriage agency to help find your match

277. men and women, now chats have made these

278. businesses fail

279. E: true

280. C: Now because when you look at him online, you go faster

281. than when you are with this person daily. Everything is

282. faster. Though later it may work or not or

283. that things go well

284. E: Like in Meetic.

285. C: Meetic is a, is a topic of which I know nothing, but I know

286. people at work, in this case two girls, who are my same

287. age, I am 32 years now ... and they are normal girls,

288. but because of lack of time or because they haven't found the appropriate

289. person to go out with, they have gone out or have been normally associated with

290. another person, so they posted an announcement there

291. E: yes, yes

292. C: and receive information on a daily basis, for I have seen it, and they contact

293. with people and stay with a person.

Meeting people through chat rooms and Meetic are activity which illustrates how this change in velocity is faster, simpler, and more effective in the social sphere. Emotional performance is constructed through the use of new technologies. The Internet is the most apt and emblematic technology that can be used in order to understand the process of the iteration of velocity, as we said above (Extract 3, line 255). 


\section{Extract 17}

179. - What ... do you think would happen if cyber-cafes disappear?

180. -Well ... but ... it would be something ... a ... a problem because if not ... but ...

181. ... well ... I often call from public phones an ... but here...

182. insert one euro... It's brief ... really brief ... really brief ... I am ... but ... it lasts enough to say 183. what I want ... but if we didn't have it ... It would be a big problem ... because communication would be...

184. ... there are people who sometimes do not have the need... the money for ...inserting in 185. public phones. Insert four euros ... Thus it would be really, really ....problematic. Using cards ...

186. ....it would be as it was before. We didn't have cyber-cafes. Of course ... in those times ... 187. ... people who... seven years ago cyber-cafés didn't exist ... then what did they do? There was

188. a sort species of smuggling ... which was for landline only. There were cards for landline

189. but it served for public phones too. Public phones were full of

190. Latin immigrants ... You dialed 900 and you could talk or you insert ...

191. coins ...

192. . / \#-I remember when I got here I started to using cards and there were phones

193. with ... lot of people ... You always had to queue ... (laughs)

If cyber cafes and call shops were to disappear, and with them the Internet and chat rooms, there would be a return to slowness, a return to queuing (Extract 17, line 193). Queueing to use the phone is a linguistic metaphor to explain the limited efficacy and immediacy brought about by the imagined disappearance of these kinds of places. It is a really important place for communicating with others. In call shops there are flat screens, web-cams, the latest technology, and the Internet is much faster than it is at home (Extract 15, line 16-18). If call shops and all their technologies were to disappear, the MC of "Velocity" would also disappear. Velocity would begin to have less effect on the use of new technology. The feature would be 'slowness'. If call shops and cyber-cafes were to disappear, the effect would be the slowness of queuing to make calls via public phones.

One of the main features of velocity, as described above, is efficacy. If cyber cafes and call shops were to disappear this efficacy would be much less evident in performance. One of the interviewees explains step by step how he would make a phone call to his country of origin if the call shop were to disappear. It would be "problematic" (Extract 17, line 180); "It would be a big problem" (Extract 17, line 183). And he would lose all the benefits the cyber cafe provides in order for him to make contact and communicate with his native land. In the past, i.e., seven years ago, according to the interviewee, there was no call shop in that neighborhood, and it would mean a return to the past if it were to disappear, a return to slowness. This is another velocity performance, understood as an emotion. The inability to go to the call shop, the lack of access to its technologies would mean a return to the past, to "smuggling" cards (Extract 17, line 188). This regression would affect velocity, i.e., speed, efficacy, and ease of communication.

Henry Lefebvre (1991, p.120) notes that modern human being 'have not yet "incorporated" to his own lifestyle speed as sequences and rhythms', thus 'nerves and senses have not yet been adequately trained by urban and technical life'. Consequently, we feel it 
is appropriate to define velocity as a very important emotional topic in the new discursive arena, which technoscience has a major input in and contributes to.

Velocity is a performance that has much in common with the linguistic metaphor of surfing in the context of Internet. Linguistic surfing is a term taken directly from the activity of riding the waves on a beach. Baricco says (2008, p.111) "Can't you see the lightness of that brain which is hooked on the foam of the waves?" Browsing, i.e., surfing, always involves velocity, but not a static velocity, but a dynamic or performative one. Surfing is a very smooth motion, but we must be quick or we will lose our balance and fall into the deep sea. Such is the emotion of velocity in ICT. Nothing more than that. Baricco uses the example of Google, and how people "breathe" through it. They breathe, run, and surf in Google. These are new new skills (Baricco, 2008, p.114). In Google, there are paths across the surface which can be followed quickly, effectively, and easily. There are rapid sequences, trajectories drawn for surfing, movements linking different points in the space of the real. Velocity is a new emotional performance, because before the advent of ICT, life was different. Before this we had to approach things one by one, to deepen relationships and intimacy in the long run. It was a patient task, a matter of study. For example, consider doing a review of scientific literature on a particular topic. We had to read a text in full in order to make sense of it, to see if it might be of interest in our research. This is not the case nowadays. You know at once. By looking for a keyword in the text we can decide if the article or book might be useful in our research. Velocity pops up fast as a complete gesture, as a performance. Thus, experience requires us to obtain a piece of information which will be enough to lead us to another piece of information. The performance is clear if we think of Baricco's mutant as a discursive evolution of Haraway's cyborg that has learned what the minimum and maximum times for doing things are. Mutant uses the search engine to see whether the text is useful to him or not. Baricco's metaphor is powerful and useful in explaining why the emotion of velocity emerges from ICT.

\section{Extract 18}

222-I use the computer in my leisure time ... for example ... when I have

223 nothing ... or I'm all alone ... and I'm not with Estefania... or my other friend is not at home... then I...

224 turn on the computer ... enter to Peru's webpage ... I read the news ... my country ... what happened

225 I enter my email ... or listen to music ... until

226 my body gets tired or I get bored and go home ... but ... I use it as a second...

227 option ... since the first one is phone. I use it when I' $m$ alone

228 / if there is something / ... "Give me five minutes" ... or "give me an hour or so ..." "Oh, I'm going to check...

229 who has written" ... "I'll check my mail" ... So I read my email ... and then I go

230 to the news from my country ... then I go to a tarot webpage...

231 any chafardeo [gossiping]... or for killing time ...... but those are the moments when ...

232. /-PAGES OF PERU ... THE TAROT .......

233. / all ... for instance I enter the site Peru dot com ... which is a page that

234 gives you ... news ... all the things happening in Lima ... everything ... everything on my country ... right? 
235 ... then, from there, when I get bored I visit a women's site on tarot...

236 it's a piece of nonsense to waste time ... to have fun ... whatever it comes

237 If I get bored... I visit a music and video clips site ... and if I continue bored,

238 well ... that's it ...

239 NO LONGER THERE ...

240 the machine is over ... and I go home ...

In this extract, we gain an understanding of what velocity means in performance: a surf bried enough to stop us from becoming bored when using a technological device. This velocity is an emotional performance which allows the individual to keep far away from the "deep", which, at this point, is an unjustified waste of time for him. It is a futile impasse (Baricco, 2008, p. 115) which destroys the flow of performance. The "deep" is boredom, and the surface is entertainment (Extract 18, lines 236-237).

In order to move quickly on the surface, everything is simplified. It is the rate at which experiences occur that allows us to put them in sequence with other things. This is the emotional performance of velocity. Everything has to be on the surface, not deep below. To facilitate the flow of communication, there must be a common language and a universal grammar based on movies or television (Baricco, 2008, p.115).

Velocity performs by looking for gestures so the cyberworld can be entered and exited equally easily. It privileges, which creates a movement, a performance, and any space generating an acceleration, an emotion. The goal of velocity is movement, performance itself. It does not seek experiences, it is an experience. As seen in the last extract, everything becomes fast, effective, and turns into an easy system until the individual becomes bored (Extract 18, lines 223-226).

Boredom is slowness. It means going back to the queue (Extract 19, line 193), a natural component of past time. The past refers to boredom and slowness. It has nothing to do with velocity, i.e., a new emotional performance characterized by speed, efficacy, and ease. This is why we now try to get rid of boredom and slowness. Baricco explains (2008, p. 116) that boredom is almost unknown to children today. They are continually doing things. They are engaged in various activities at different levels and in different contexts. If a child slows down, he falls off his bicycle. The metaphor of the bicycle helps us to understand the performance of velocity, the need for fast and constant movement to avoid getting bored; for example, surfing the net, and at the superior level: multitasking. Baricco (2008, p. 116) defines the phenomenon of multi-tasking using the example of a child who can play Nintendo, eat a hot-dog, phone his grandmother, watch cartoons on TV, pat the dog with one foot and whistle the T-mobile tune. Or a teenager who does his homework while chatting on Messenger, using his iPod, sending an sms, searching Google for the address of a pizzeria and playing with a rubber ball. Multi-tasking, of course, must be done quickly. Otherwise, it would produce negative emotions. Not replying to an email after a reasonable interval of time, not being available on Messenger, or not answering our cell phone have bad consequences in everyday life. Velocity, therefore, must be a continuous and constant performance. Whether it is a matter of genius or idiocy, the brain hungrily seeks more velocity.

Surfing must always be fast. It is like riding a bicycle. We never stop to see the sea, the beach or the boats, because we see them while we are pedaling. And if we stop, it is only for a short time. Then we continue. 
Using new technology helps us to get closer to others, and this we do through language. Thanks to language we can produce an emotional performance of velocity, in an instantaneous and intuitive way. We have come to understand ICT as an extension of our own body, as in Haraway's cyborg model. A comprehensive symbiosis as the mutant concept that Baricco developed Thus, we no longer see new technologies as cold and impersonal machines. Instead, we see them, emotionally speaking, as part of us. Before going to bed or when we wake up in the morning, often one of the first things we do is to check our inbox for new emails, and this kind of act is already part of our everyday life.

In this sense, velocity is a basic emotional performance which should be considered a primary emotion in the study of ICT. If we now go back to the first part of this analysis (Extract 1), we can understand velocity more comprehensively as velocity, the use of ICT, progress, the relationship with others, the mastery of time, and finally, the features of speed, efficacy, and ease.

Have we now understood this transition? Individuals see new technologies as parts of themselves, allowing them to interact with others, laugh or cry in front of a flat screen, but it is as if we are crying or laughing with the person on the other side of the screen, our son or our friends. We do this through language, offering an infinite number of emotions, in what we refer to as an emotional performance. Velocity is always present in this relationship. Velocity is a constant when we use new technologies. Velocity is what allows us to move away from viewing technologies as being cold and unemotional, to seeing them as being part of us and producing real emotions. Velocity allows us to understand that machines are extensions of our bodies, an integral part of the body, and we no longer believe they are just machines. The transition from the model of the cyborg, (body and machine together), to the mutant in which there is no longer any distinction between the body and the machine, is part of an advanced biology, the natural evolution of human beings.

\section{Discussion}

Emotions have a strong relationship with language. We can express emotions through language. To express emotions means establishing that we have something in common with others. We can analyse the expression of emotions using Judith Butler's concept of emotional performance. Emotions are not fixed, defined, or static. They are constantly evolving, continuously implied in an iteration process, and they occur through language, which is natural and subjective. This constant iteration makes them appear and disappear from the discursive arena. We can see how forgotten emotions are abandoned and new ones are discovered in technoscience (Belli, Harré, \& Íñiguez, in press). Emotions undergo constant evolution in everyday narrative and are expressed mostly in technoscience. In fact, the term emotion can be associated with very specific areas of technoscience, thus emotional expressions come into play in the discursive arena. The emergence of concepts such as techno-disembodiment, or the emotional connection between people and new technologies, namely the concept of Nikolas Rose's machine-affectivity, are examples of the current scope of technoscience. They enable us to use the concept of disclosure to think of love in the age of technoscience.

In this article, we have dealt with the concept of emotional performance, which we use to argue our thesis that emotions change in narrative. An infinite variety of emotions occur in the individual when using new technologies to communicate with others. They can range 
from boredom to happiness, from anger to love. We do not recognize them independently, since only through language, which is irrational and subjective, can we experience them. The performance which emerges in the course of the analysis is velocity. Velocity has three features: speed, efficacy, and ease. They are still seen as cold and unemotional machines. But throughout the analysis we have shown how, due to the performance of velocity, the individual becomes a mutant. The technologies are part of our own body and they are no longer cold and alien machines, since we have been metabolized into them. Their use has become part of our daily practices. This allows us to feel excited, and to express our excitement through language, using the emotional performance of velocity to indicate what is happening to us.

People can feel happy or bored using new technology, but the relationship, or conflict, between the individual, society, and ICT is always discursive, always constructed as a discursive performance, and in this performance, velocity emerges. What is expressed is velocity, and not happiness or boredom. We talk to others using this category of velocity, which changes continuously. It can never be defined.

The extension of our own body constructed discursively provides the emotional performance of velocity. Through this characteristic it is argued that our discursive performance is defined. It may be that the interviewee feels happy because she has purchased a technology, but that is something we do not know. Feeling happiness on purchasing a new blackberry or experiencing boredom as a consequence of having a previous version are reasons for wanting to change things. ${ }^{2}$

\section{References}

Aviram, I., \& Amichai-Hamburger, Y. (2005). Online infidelity: Aspects of dyadic satisfaction, selfdisclosure, and narcissism. Journal of Computer-Mediated Communication, 10(3), 45-69.

Baricco, A. (2008). Los bárbaros: Ensayo sobre la mutación. Barcelona: Anagrama.

Baudrillard, J. (1990). Seduction. New York: St. Martin's.

Bauman, Z. (2006). Liquid fear. Cambridge: Polity Press.

Belli, S., \& Íñiguez-Rueda, L. (2008). El estudio psicosocial de las emociones: Una revisión y discusión de la investigación actual. PSICO, 39(2), 139-151.

Belli, S., Harré, R., \& Íñiguez-Rueda, L. (2010). What is love? Discourse about emotions in social Sciences. Human Affairs, 20, 249-270.

Brown, S.D. (2005). Collective emotions: Artaud's nerves. Culture and Organization, 11(4), 235-247.

Brown, S. D., Stenner, P. (2001). Being affected: Spinoza and the psychology of emotion. International Journal of Group Tensions, 30(1), 81-105.

Butler, J. (1990). Gender trouble. Continental Feminism Reader. London: Routledge.

Butler, J. (1993). Bodies that matter: On the discursive limits of sex. London: Routledge.

Butler, J. (1997). Excitable speech: A politics of the performative. London: Routledge.

Gergen, K. J. (1990). Affect and organization in postmodern society. In S. Srivastva, \& D. L. Cooperrider (Eds.), Appreciative management and leadership: The power of positive thought and action in organizations (pp. 153-174). Washington: Jossey-Bass.

Gibbs, R. W. J. (2006). Embodiment and cognitive science. Cambridge: Cambridge University Press.

Gregson, N., \& Rose, G. (2000). Taking Butler elsewhere: Performativities, spatialities and subjectivities. Environment and Planning D, 18(4), 433-452.

Haraway, D. (1989). Primate visions: Gender, race, and nature in the world of modern science. New York: Routledge. 
Haraway, D. (1990). A manifesto for cyborgs: Science, technology, and socialist. New York: Routledge. Haraway, D. (1995). Ciencia, cyborgs y mujeres: La reinvención de la naturaleza. Valencia: Publ. Universitat de Valencia.

Harré, R. (1984). Social elements as mind. British Journal of Medical Psychology, 57(2), 127-135.

Hollinger, V. (2000). Cyborgs and citadels/between monsters, goddess, and cyborgs. Signs: Journal of Women in Culture \& Society, 25, 577-601.

Illouz, E. (2007). Cold intimacies: The making of emotional capitalism. London: Polity.

Íñiguez, L. (2005). Nuevos debates, nuevas ideas y nuevas prácticas en la Psicología social de la era 'post-construccionista'. Athenea Digital 8, 24-60.

James, P. \& Carkeek, F. (1997). Techno-disembodiment. Virtual politics: Identity and community in cyberspace. London: Springer, 1997.

Lefebvre, H. (1991). The production of space. London: Blackwell publishers.

Leudar, I. (1995). Reporting political arguments. In Van Eemeren, (Eds.), Reconstruction and application: Proceedings of the third conference on argumentation (Vol. 3, pp. 42-59). Amsterdam: Sic Sat.

Leudar, I. (1998). Who is Martin McGuiness 1: On contextualizing reported political talk. Dialogue Analysis, 6, 217-224.

Michael, M. (1996). Constructing identities: The social, the nonhuman and change. London: Sage.

Michael, M. (Ed.). (2000). Reconnecting culture, technology and nature: From society to heterogeneity. London: Routledge.

Michael, M. (2004). Reconnecting culture, technology, and nature: From society to heterogeneity. London: Ebrary.

Michael, M. (2006). Technoscience and everyday life: The complex simplicities of the mundane. New York: Open University Press.

Oatley, K., \& Jenkins, J. M. (1992). Human emotions: Function and dysfunction. Annual Review of Psychology, 43, 55-85.

Qian, H., \& Scott, C. R. (2007). Anonymity and self-disclosure on weblogs. Journal of ComputerMediated Communication, 12(4), 1428-1451.

Rose, N. (1983). Effects of rational emotive education and rational emotive education plus rational emotive imagery on the adjustment of disturbed and normal elementary school children. Ann Arbor, MI: ProQuest Information \& Learning.

Sacks, H. (1992). Lectures on conversation: Vol 1 \& 2. Oxford: Basil Blackwell.

Schaub, E. L. (1933). Spinoza: His personality and his doctrine of perfection. Monist, 43, 1-22.

Watson, D. R. (1987). Interdisciplinary considerations in the analysis of pro-terms. Talk and Social Organisation, 5, 261-289.

Wittgenstein, L. (1958). Philosophical investigations. New York: Macmillan.

Department of Philosophy, Universidad Carlos III de Madrid

Madrid, Spain

E-mail:simone.belli@uc3m.es;

Psychology Dept, Georgetown University,

Washington, DC 20057, USA

E-mail: harre@georgetown.edu

Department of Social Psychology, Universitat Autonoma de Barcelona

08192 Bellaterra (Cerdanyola), Spain

E-mail: lupicinio.iniguez@uab.cat 